\title{
Fabrication of Reproducible and Selective Ammonia Vapor Sensor-Pellet of Polypyrrole/Cerium Oxide Nanocomposite for Prompt Detection at Room Temperature
}

\author{
Ahmad Husain 1,*DiD, Salma Ahmed Al-Zahrani ${ }^{2}$, Ahmed Al Otaibi ${ }^{2}$, Imran Khan ${ }^{3}$, \\ Mohammad Mujahid Ali Khan ${ }^{3}$, Abeer Mohamed Alosaimi ${ }^{4}$, Anish Khan 5,6,*(D), Mahmoud Ali Hussein ${ }^{5,7}$, \\ Abdullah M. Asiri ${ }^{5,6}$ and Mohammad Jawaid ${ }^{8}$ (D)
}

check for updates

Citation: Husain, A.; Al-Zahrani, S.A.; Al Otaibi, A.; Khan, I.; Mujahid Ali Khan, M.; Alosaimi, A.M.; Khan, A.; Hussein, M.A.; Asiri, A.M.; Jawaid, M. Fabrication of Reproducible and Selective Ammonia Vapor Sensor-Pellet of

Polypyrrole/Cerium Oxide Nanocomposite for Prompt Detection at Room Temperature. Polymers 2021, 13, 1829. https://doi.org/10.3390/ polym13111829

Academic Editor: Jin-Hae Chang

Received: 19 May 2021

Accepted: 22 May 2021

Published: 31 May 2021

Publisher's Note: MDPI stays neutra with regard to jurisdictional claims in published maps and institutional affiliations.

Copyright: (c) 2021 by the authors. Licensee MDPI, Basel, Switzerland. This article is an open access article distributed under the terms and conditions of the Creative Commons Attribution (CC BY) license (https:/ creativecommons.org/licenses/by/ $4.0 /)$
1 Department of Applied Chemistry, Faculty of Engineering and Technology, Aligarh Muslim University, Aligarh 202002, India

2 Chemistry Department, Faculty of Science, University of Ha'il, P.O. Box 2440, Ha'il 81451, Saudi Arabia; s.alzahrane@uoh.edu.sa (S.A.A.-Z.); ahmed.alotaibi@uoh.edu.sa (A.A.O.)

3 Applied Science and Humanities Section, Faculty of Engineering and Technology, University Polytechnic, Aligarh Muslim University, Aligarh 202002, India; imrannano@gmail.com (I.K.);

mujahidchemistry@gmail.com (M.M.A.K.)

4 Department of Chemistry, Faculty of Science, Taif University, P.O. Box 11099, Taif 21944, Saudi Arabia; abeer_alosaim@hotmail.com

5 Chemistry Department, Faculty of Science, King Abdulaziz University, P.O. Box 80203, Jeddah 21589, Saudi Arabia; mahussein73@yahoo.com (M.A.H.); asiri2@kau.edu.sa (A.M.A.)

6 Center of Excellence for Advanced Materials Research, King Abdulaziz University, P.O. Box 80203, Jeddah 21589, Saudi Arabia

7 Chemistry Department, Faculty of Science, Assiut University, Assiut 71516, Egypt

8 Laboratory of Biocomposite Technology, Institute of Tropical Forestry and Forest Products (INTROP), University Putra Malaysia, UPM Serdang, Selangor 43400, Malaysia; jawaid@upm.edu.my

* Correspondence: ahmadhusain2065@gmail.com (A.H.); anishkhan97@gmail.com (A.K.)

Abstract: Polypyrrole (PPy) and polypyrrole/cerium oxide nanocomposite $\left(\mathrm{PPy} / \mathrm{CeO}_{2}\right)$ were prepared by the chemical oxidative method in an aqueous medium using anhydrous ferric chloride $\left(\mathrm{FeCl}_{3}\right)$ as an oxidant. The successful formulation of materials was confirmed by Fourier transform infrared spectroscopy (FT-IR), X-ray diffraction (XRD), thermogravimetric analysis (TGA), scanning electron microscopy (SEM), and transmittance electron microscopy (TEM). A four-in-line probe device was used for studying DC electrical conductivity and ammonia vapor sensing properties of $\mathrm{PPy}$ and $\mathrm{PPy} / \mathrm{CeO}_{2}$. The significant improvement in both the conductivity and sensing parameters of $\mathrm{PPy} / \mathrm{CeO}_{2}$ compared to pristine PPy reveals some synergistic/electronic interaction between PPy and cerium oxide nanoparticles $\left(\mathrm{CeO}_{2} \mathrm{NPs}\right)$ working at molecular levels. The initial conductivity (i.e., conductivity at room temperature) was found to be $0.152 \mathrm{Scm}^{-1}$ and $1.295 \mathrm{Scm}^{-1}$ for PPy and $\mathrm{PPy} / \mathrm{CeO}_{2}$, respectively. Also, $\mathrm{PPy} / \mathrm{CeO}_{2}$ showed much better conductivity retention than pristine PPy under both the isothermal and cyclic ageing conditions. Ammonia vapor sensing was carried out at different concentration $(0.01,0.03,0.05,0.1,0.2,0.3,0.4$, and $0.5 \mathrm{vol} \%)$. The sensing response of $\mathrm{PPy} / \mathrm{CeO}_{2}$ varied with varying concentrations. At $0.5 \mathrm{vol} \%$ ammonia concentration, the $\%$ sensing response of PPy and $\mathrm{PPy} / \mathrm{CeO}_{2}$ sensor was found to be $39.1 \%$ and $93.4 \%$, respectively. The sensing efficiency of the PPy $/ \mathrm{CeO}_{2}$ sensor was also evaluated at 0.4. 0.3, 0.2, 0.1, 0.05, 0.03, and 0.01 vol $\%$ ammonia concentration in terms of \% sensing response, response/recovery time, reversibility, selectivity as well as stability at room temperature.

Keywords: polypyrrole; cerium oxide; nanocomposite; DC electrical conductivity; ammonia vapor sensing 


\section{Introduction}

Recently, due to rapid industrial development and uncontrolled human activities, the release of toxic gases into the environment has increased many folds. Ammonia is one of the most harmful environmental pollutants. If the concentration of ammonia in the environment exceeds $300 \mathrm{ppm}$, it may damage the human cell [1-5]. It may also cause many diseases of the eyes, kidneys, liver, respiratory tract, as well as skin. Hence, for the sake of our ecosystem and good human health, the detection and monitoring of highly toxic ammonia at room temperature is a necessity [1-5]. In the past few years, conducting polymers have been used for the fabrication of highly efficient chemiresistive ammonia sensor working at ambient temperature. Lately, a great deal of research was carried out in the arena of conducting polymers as they possess good electrical properties and find application in various fields of science and technology, especially in gas/vapor sensing devices [1-20].

Amongst the several conducting polymers present today, polypyrrole (PPy) has garnered great interest because of its high conductivity, high environmental and thermal stability, low toxicity, and facile synthesis. The important thing about PPy based sensors is that they can be operated at room temperature. The electrical and morphological properties of PPy can easily be tuned by controlling both the polymerization method and doping process. The sensors based on PPy showed quick response at room temperature even at very low concentration of analyte gases/vapors. The main drawback of these sensors is poor selectivity and long-term stability [1-6]. Both the sensing performance and electrical conductivity of pristine PPy could be enhanced significantly by the formulation of its nanocomposites. Over the years, different types of nano-filler-such as metal/semi-metal oxides, graphene, carbon nanotubes, etc.- have been incorporated into the PPy matrix. The improved properties of nanocomposites are explained by the electronic/synergistic interaction between PPy chains and nano-filler acting at molecular levels [15-17,21-25].

Among them, metal oxides are cheap, environmentally stable and can be easily obtained $[26,27]$. Cerium oxide $\left(\mathrm{CeO}_{2}\right)$ is abundant as well as an attractive rare earth oxide which is also the cheapest electrode materials amongst the existing metal oxides today. It finds application in various fields such as preventing corrosion, thermal coatings, electromagnetic shielding, as well in electrochemical cells [28-31]. It exists in two oxidation states-i.e., +3 and +4 , respectively-although most rare earth metals exist only in the +3 oxidation state. As it possesses the ability to transform its oxidation state, it is used in a variety of applications such as solid oxide fuel cells as well as catalytic converters [32,33]. Also, $\mathrm{CeO}_{2}$ has attracted great attention as it possesses optical and thermal properties and unique characteristics such as being non-toxic, biocompatible, and having the ability to store oxygen [34]. There are several studies reporting the formulation of composites of PPy with $\mathrm{CeO}_{2}$ and its utilization in chemical and bio-sensing devices.

Khan et al. fabricated a highly sensitive and sophisticated sensor of $\mathrm{PPy} / \mathrm{CeO}_{2} /$ glassy carbon electrode for electrochemically detecting flupirtine maleate [35]. Karimi et al. synthesized an $\mathrm{H}_{2} \mathrm{O}_{2}$ electrochemiluminescence (ECL) sensor by polypyrrole-dodecylbenzene sulfate-cerium oxide nanocomposite on a Pt electrode which possessed a very low detection limit [36]. The effect of $\mathrm{CeO}_{2}$ on the structure, morphology, as well as dielectric properties of PVA/PPy blend composites, was studied by Mohanpriya et al. [37]. The DC conductivity as well as sensing behavior of nanostructured polypyrrole- $\mathrm{CeO}_{2}$ composites towards LPG was studied by Seema et al. [38]. The effect $\mathrm{CeO}_{2}$ incorporation has on the ion-exchange properties of polypyrrole films doped by dodecylsulfate was investigated by Benmouhoub et al. [39].

To our best knowledge, $\mathrm{PPy} / \mathrm{CeO}_{2}$ nanocomposite is not utilized for ammonia vapor sensing, yet. Hence, motivated by exceptional results of $\mathrm{PPy} / \mathrm{CeO}_{2}$ based sensors towards a large number of the analyte, we have prepared PPy and PPy/CeO $\mathrm{CeO}_{2}$ through chemical oxidative polymerization. The prepared materials were characterized by several advanced techniques. DC electrical conductivity retention ability of PPy and $\mathrm{PPy} / \mathrm{CeO}_{2}$ was also tested under isothermal and cyclic ageing conditions. Ammonia vapor sensing properties 
of PPy and $\mathrm{PPy} / \mathrm{CeO}_{2}$ based sensor-pellets at room temperature were evaluated and compared. The sensing efficiency of the $\mathrm{PPy} / \mathrm{CeO}_{2}$ sensor was evaluated at different ammonia concentrations viz. $0.01,0.03,0.05,0.1,0.2,0.3,0.4$, and $0.5 \mathrm{vol} \%$ with respect to $\%$ sensing response, response/recovery time, reproducibility, selectivity and stability.

To our best knowledge, $\mathrm{PPy} / \mathrm{CeO}_{2}$ nanocomposite is utilized first time as the pellet-shaped sensor for fast, reversible and selective detection of ammonia vapor at room temperature.

\section{Experimental}

\subsection{Materials}

Pyrrole 99\% (Sigma-Aldrich, Aligarh, India), anhydrous ferric chloride $\left(\mathrm{FeCl}_{3}\right)$ and methanol (Fischer Scientific, Aligarh, India), cerium oxide nanoparticles $\left(\mathrm{CeO}_{2} \mathrm{NPs}\right)$ having particle size $20-50 \mathrm{~nm}$ from Platonic Nanotech Pvt. Ltd., Jharkhand, India were used as received. Double-distilled water was used in synthesis and other experiments.

\subsection{Synthesis of $\mathrm{PPy}$ and $\mathrm{PPy} / \mathrm{CeO}_{2}$}

$\mathrm{PPy}$ and $\mathrm{PPy} / \mathrm{CeO}_{2}$ were synthesized by in-situ oxidative polymerization method in an aqueous medium using $\mathrm{FeCl}_{3}$ as an oxidant. In the first step of the synthesis, in $100 \mathrm{~mL}$ of double-distilled water, $0.03 \mathrm{~mol}$ of pyrrole was agitated. Then an aqueous solution of $\mathrm{FeCl}_{3}$ (0.09 mol) in $100 \mathrm{~mL}$ double-distilled water was prepared. Subsequently, $\mathrm{FeCl}_{3}$ solution was added dropwise to the aqueous suspension of pyrrole during continuous stirring condition at room temperature. The stirring was continued for $10 \mathrm{~h}$ that led to the formation of a black slurry. This step was followed by simultaneous filtration and washing of thus obtained black colored slurry with double-distilled water and methanol. Thus, obtained black colored PPy was dried in an air oven at $60^{\circ} \mathrm{C}$ for $12 \mathrm{~h}$, converted to a fine powder and was kept in a desiccator for carrying out further investigations.

An identical procedure was adopted to synthesize the $\mathrm{PPy} / \mathrm{CeO}_{2}$. First of all, $0.03 \mathrm{~mol}$ of pyrrole was agitated in $100 \mathrm{~mL}$ of double-distilled water. Then, $500 \mathrm{mg}$ of $\mathrm{CeO}_{2} \mathrm{NPs}$ were transferred into the above aqueous suspension of pyrrole. Then, pyrrole and $\mathrm{CeO}_{2} \mathrm{NPs}$ suspension were ultrasonicated for $1 \mathrm{~h}$ intended for the adsorption of pyrrole molecules on the surface of $\mathrm{CeO}_{2} \mathrm{NPs}$. After that, $\mathrm{FeCl}_{3}$ solution was added dropwise to the aqueous suspension of pyrrole and $\mathrm{CeO}_{2}$ NPs during continuous stirring condition at room temperature for $10 \mathrm{~h}$, which produced a black colored slurry of $\mathrm{PPy} / \mathrm{CeO}_{2}$. Thus, prepared slurry of PPy $/ \mathrm{CeO}_{2}$ was filtered with continuous washing with double-distilled water and methanol. Thus, produced black colored $\mathrm{PPy} / \mathrm{CeO}_{2}$ was dried in an air oven at $60{ }^{\circ} \mathrm{C}$ for $12 \mathrm{~h}$, converted to a fine powder and was kept in a desiccator for carrying out further investigations (Figure 1).



Figure 1. Schematic diagram showing various steps involved in the synthesis of $\mathrm{PPy} / \mathrm{CeO}_{2}$.

\subsection{Characterization and Instrumentation}

In order to study the crystalline structure and phase of $\mathrm{PPy}, \mathrm{CeO}_{2} \mathrm{NPs}$, and $\mathrm{PPy} / \mathrm{CeO}_{2}$, an $\mathrm{X}$-ray beam diffractometer (Shimadzu XRD, model 6100, Kyoto, Japan) (Cu K $\alpha$ radiation $(1.540 \AA)$ ) operating at a voltage of $30 \mathrm{kv}$ and $2 \theta$ value between 5 and $80^{\circ}$ was employed. In order to record the Fourier transform infrared (FT-IR) spectra of PPy, $\mathrm{CeO}_{2} \mathrm{NPs}$ and 
$\mathrm{PPy} / \mathrm{CeO}_{2}$ in the range of $400-4000 \mathrm{~cm}^{-1}$ a Perkin-Elmer-1725 (Waltham, MA, USA) on $\mathrm{KBr}$ pellets was used. The surface morphological studies of $\mathrm{PPy}$ and $\mathrm{PPy} / \mathrm{CeO}_{2}$ were performed using a JSM-6510-LV (JEOL, Tokyo, Japan) scanning electron microscope and JEM-2100 (JEOL, Tokyo, Japan) transmission electron microscope, respectively. In order to carry out the thermogravimetric analysis a Shimadzu $60 \mathrm{H}$ instrument (Kyoto, Japan) was used where the samples were heated in the range $50{ }^{\circ} \mathrm{C}$ to $900{ }^{\circ} \mathrm{C}$ at a rate of $15^{\circ} \mathrm{C} \mathrm{min}-1$ in an atmosphere of nitrogen with a flow rate of $150 \mathrm{~mL} / \mathrm{min}$.

DC electrical conductivity and ammonia vapor sensing experiments were done by a four-in-line probe instrument attached with a PID controlled oven manufactured by Scientific Equipment, Roorkee, India. The equation used for the calculation of electrical conductivity is

$$
\sigma=[\ln 2(2 \mathrm{~S} / \mathrm{W})] /[2 \pi \mathrm{S}(\mathrm{V} / \mathrm{I})]
$$

where: I, V, W, S, and $\sigma$ represent the current $(\mathrm{A})$, voltage $(\mathrm{V})$, the thickness of the pellet $(\mathrm{cm})$ probe spacing $(\mathrm{cm})$ and conductivity $\left(\mathrm{Scm}^{-1}\right)$, respectively [40-42].

The pellets of PPy and PPy/ $\mathrm{CeO}_{2}$ for conductivity and sensing studies were made by a hydraulic pressure machine at $80 \mathrm{kN}$ pressure applied for $120 \mathrm{~s} .200 \mathrm{mg}$ of each sample was used for the preparation of Pellets. Different pellets were used in conductivity and sensing experiments.

In isothermal ageing experiments, the pellet of PPy and $\mathrm{PPy} / \mathrm{CeO}_{2}$ were heated at 50, 70, 90, 110, and $130{ }^{\circ} \mathrm{C}$ in PID controlled air oven. The electrical conductivity was calculated at a particular temperature at an interval of $10 \mathrm{~min}$. In cyclic ageing experiments, the conductivity was determined for four successive cycles starting from $50{ }^{\circ} \mathrm{C}$ to $130{ }^{\circ} \mathrm{C}[43,44]$.

\section{Results and Discussion}

\subsection{Fourier Transform Infrared Spectroscopic (FT-IR) Studies}

The IR spectra of PPy, $\mathrm{CeO}_{2} \mathrm{NPs}$, and $\mathrm{PPy} / \mathrm{CeO}_{2}$ are shown in Figure 2. In PPy spectrum (Figure 2a), the peak at $3430.8 \mathrm{~cm}^{-1}$ is owing to the $\mathrm{N}-\mathrm{H}$ stretching vibrations. The peak at $1550.8 \mathrm{~cm}^{-1}$ is a result of $C=C$ stretching vibrations. The peak at $1459.9 \mathrm{~cm}^{-1}$ corresponds to the $\mathrm{C}-\mathrm{C}$ stretching and the peaks appeared $1307.1 \mathrm{~cm}^{-1}$ and $1187.3 \mathrm{~cm}^{-1}$ may be due to the $\mathrm{C}=\mathrm{N}$ bending and $\mathrm{C}-\mathrm{N}$ vibration, respectively. The $=\mathrm{C}-\mathrm{H}$ bending is shown by the peak at $1044.8 \mathrm{~cm}^{-1}$, while the peak at $791.9 \mathrm{~cm}^{-1}$ is attributed to the vibrations of $\mathrm{C}-\mathrm{H}$ bonds. The peak at $922.5 \mathrm{~cm}^{-1}$ is ascribed to the $=\mathrm{C}-\mathrm{N}^{+}-\mathrm{C}$ stretching vibration. This peak at $922.5 \mathrm{~cm}^{-1}$ shows that PPy was effectively oxidized and doped by $\mathrm{FeCl}_{3}$ into positively charged species that act as charge carriers (i.e., polarons/bipolarons) $[17,23,24]$.

In the spectrum of $\mathrm{CeO}_{2} \mathrm{NPs}$ (Figure $2 b$ ), peak is observed at $1625.7 \mathrm{~cm}^{-1}$ because of the $\mathrm{O}-\mathrm{H}$ stretching vibration of the water molecule. The peaks at $1321.5 \mathrm{~cm}^{-1}$ and $1066.4 \mathrm{~cm}^{-1}$ can be related to the carbonate-like species formation on the surface of $\mathrm{CeO}_{2}$ NPs. The peak at $854.3 \mathrm{~cm}^{-1}$ is because of enveloping of the phonon band of $\mathrm{CeO}_{2} \mathrm{NPs}$. The broad peak at $633.5 \mathrm{~cm}^{-1}$ is due to the vibrational mode of O-Ce-O bonds [45-47].

In the spectrum of $\mathrm{PPy} / \mathrm{CeO}_{2}$ (Figure 2c), all the characteristic peaks of PPy were weakened and observed at smaller wavenumbers (Table 1). The weakening and shifting of peaks may be due to some synergistic/electronic interaction between PPy chains and molecular interacting $\mathrm{CeO}_{2} \mathrm{NPs}$ working at molecular levels. There was no visible peak of $\mathrm{CeO}_{2} \mathrm{NPs}$ in $\mathrm{PPy} / \mathrm{CeO}_{2}$ spectrum which showed encapsulation of $\mathrm{CeO}_{2} \mathrm{NPs}$ into PPy matrix (can be confirmed by SEM and TEM images). 


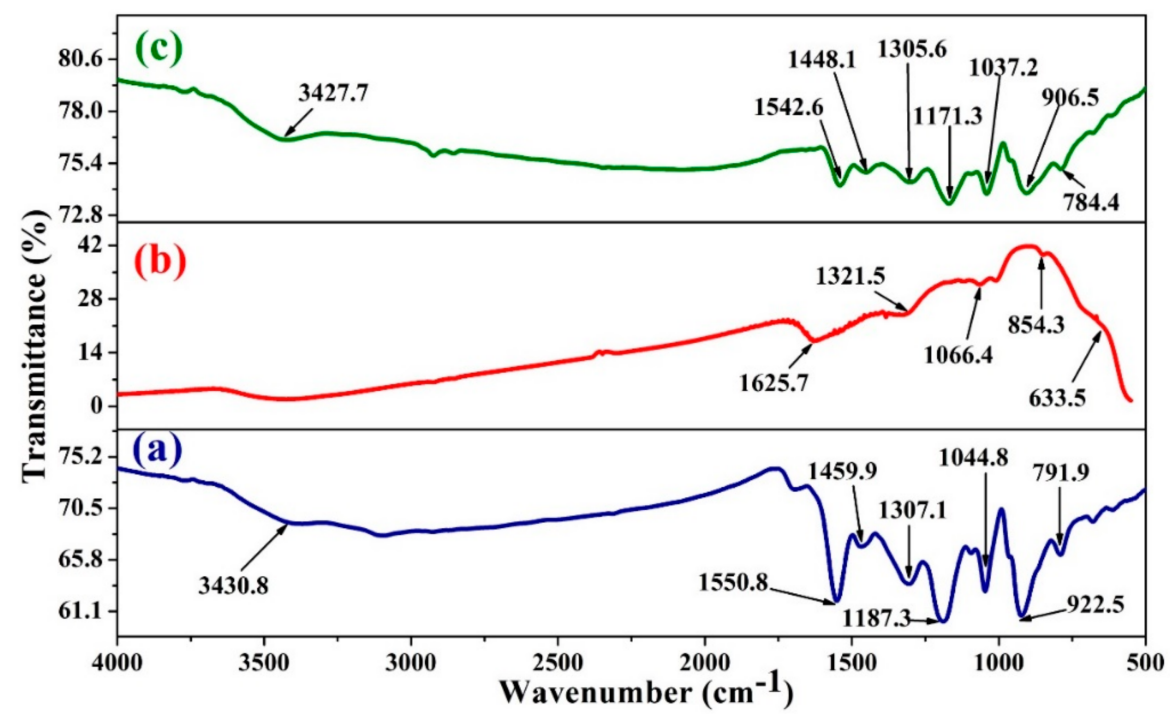

Figure 2. FTIR spectra of: (a) PPy, (b) $\mathrm{CeO}_{2} \mathrm{NPs}$, and (c) $\mathrm{PPy} / \mathrm{CeO}_{2}$.

Table 1. Characteristic peaks of PPy and PPy/ $\mathrm{CeO}_{2}$.

\begin{tabular}{cccccccccc}
\hline S. No. & Materials & $\begin{array}{c}\mathbf{N}-\mathbf{H} \\
\left(\mathbf{c m}^{-\mathbf{1}}\right)\end{array}$ & $\begin{array}{c}\mathrm{C}=\mathrm{C} \\
\left(\mathbf{c m}^{-\mathbf{1}}\right)\end{array}$ & $\begin{array}{c}\mathrm{C}-\mathrm{C} \\
\left(\mathbf{c m}^{\mathbf{1}}\right)\end{array}$ & $\begin{array}{c}\mathrm{C}=\mathbf{N} \\
\left(\mathbf{c m}^{\mathbf{1}}\right)\end{array}$ & $\begin{array}{c}\mathrm{C}-\mathbf{N} \\
\left(\mathbf{c m}^{\mathbf{1}}\right)\end{array}$ & $\begin{array}{c}=\mathrm{C}-\mathrm{H} \\
\left(\mathbf{c m}^{\mathbf{1}}\right)\end{array}$ & $\begin{array}{c}\mathrm{C}=\mathbf{N}^{+}-\mathrm{C} \\
\left(\mathbf{c m}^{-\mathbf{1}}\right)\end{array}$ & $\begin{array}{c}\mathrm{C}-\mathrm{H} \\
\left(\mathbf{c m}^{\mathbf{1}}\right)\end{array}$ \\
\hline 1. & $\mathrm{PPy}$ & 3430.8 & 1550.8 & 1459.9 & 1307.1 & 1187.3 & 1044.8 & 922.5 & 791.9 \\
\hline 2. & $\mathrm{PPy} / \mathrm{CeO}_{2}$ & 3427.7 & 1542.6 & 1448.1 & 1305.6 & 1171.3 & 1037.2 & 906.5 & 784.4 \\
\hline
\end{tabular}

\subsection{X-ray Diffraction (XRD) Studies}

The XRD spectra of $\mathrm{PPy}, \mathrm{CeO}_{2} \mathrm{NPs}$ and $\mathrm{PPy} / \mathrm{CeO}_{2}$ are displayed in Figure 3. In PPy (Figure $3 a$ ), the broad band between $2 \theta=20-30^{\circ}$, having a maximum at $2 \theta=24.87^{\circ}$ showed pyrrole was successfully polymerized to PPy. The broad also confirms that PPy was amorphous in nature $[17,23,24]$.

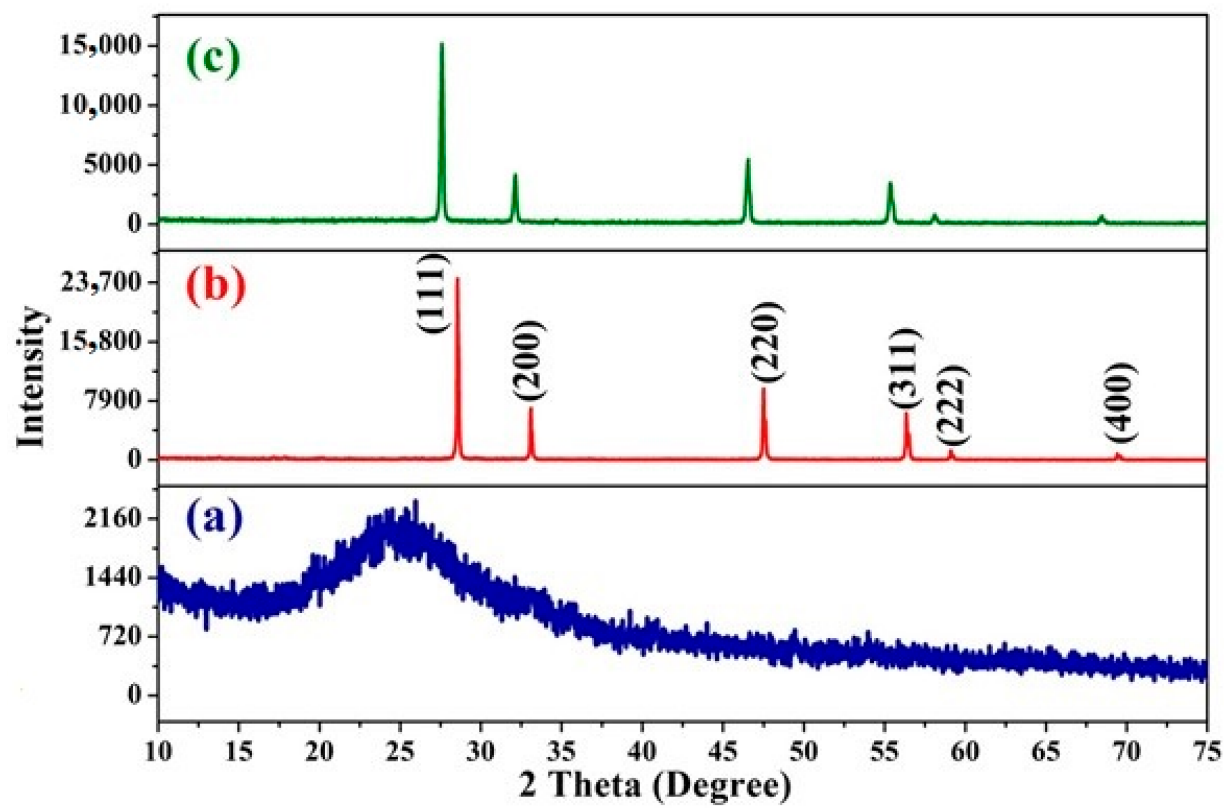

Figure 3. XRD spectra of: (a) $\mathrm{PPy},(\mathbf{b}) \mathrm{CeO}_{2} \mathrm{NPs}$ and (c) $\mathrm{PPy} / \mathrm{CeO}_{2}$. 
The XRD spectrum of $\mathrm{CeO}_{2} \mathrm{NPs}$ (Figure $3 \mathrm{~b}$ ) consists of several peaks at $2 \theta=28.57^{\circ}$, $33.14^{\circ}, 47.59^{\circ}, 56.43^{\circ}, 59.1^{\circ}$, and $69.56^{\circ}$ which are related to the crystalline planes (111), (200), (220), (311) (222), and (400), respectively [45-47].

In $\mathrm{PPy} / \mathrm{CeO}_{2}$ (Figure 3c), all the characteristic crystalline planes of $\mathrm{CeO}_{2} \mathrm{NPs}$ were observed to confirm the presence of $\mathrm{CeO}_{2} \mathrm{NPs}$ in $\mathrm{PPy} / \mathrm{CeO}_{2}$. The peaks of $\mathrm{CeO}_{2} \mathrm{NPs}$ were observed at $2 \theta=27.54^{\circ}, 32.17^{\circ}, 46.52^{\circ}, 55.38^{\circ}, 58.16^{\circ}$, and $68.50^{\circ}$ respectively. The most significant observation was the shifting of peaks of $\mathrm{CeO}_{2} \mathrm{NPs}$ towards lower $2 \theta$ angles along with a decrease in intensity. The observed peak shifting along with a decrease in intensity can be confirmation of the thorough incorporation of $\mathrm{CeO}_{2} \mathrm{NPs}$ into the PPy matrix.

\subsection{Morphological Studies (SEM and TEM)}

The scanning electron micrographs and transmittance electron micrographs of PPy and $\mathrm{PPy} / \mathrm{CeO}_{2}$ are shown in Figure 4. From the SEM and TEM images of PPy (Figure 4a,c, respectively), it is evident that the morphology of pristine PPy consists of several globular particles which have been agglomerated $[17,23,24]$. In the case of $\mathrm{PPy} / \mathrm{CeO}_{2}$ (Figure $\left.4 \mathrm{~b}\right), \mathrm{a}$ similar morphology as pristine PPy is observed consisting of clusters of globular particles. The most important point is that there was no distinct $\mathrm{CeO}_{2} \mathrm{NPs}$ in the SEM image of $\mathrm{PPy} / \mathrm{CeO}_{2}$ indicating the successful polymerization of pyrrole on the surface of $\mathrm{CeO}_{2}$ NPs. The presence of $\mathrm{CeO}_{2}$ NPs into the matrix of PPy can be seen in the TEM image of $\mathrm{PPy} / \mathrm{CeO}_{2}$ (Figure $4 \mathrm{~d}$ ). The homogeneous and complete incorporation of $\mathrm{CeO}_{2} \mathrm{NPs}$ into the PPy matrix confirmed the successful formulation of $\mathrm{PPy} / \mathrm{CeO}_{2}$ nanocomposite.

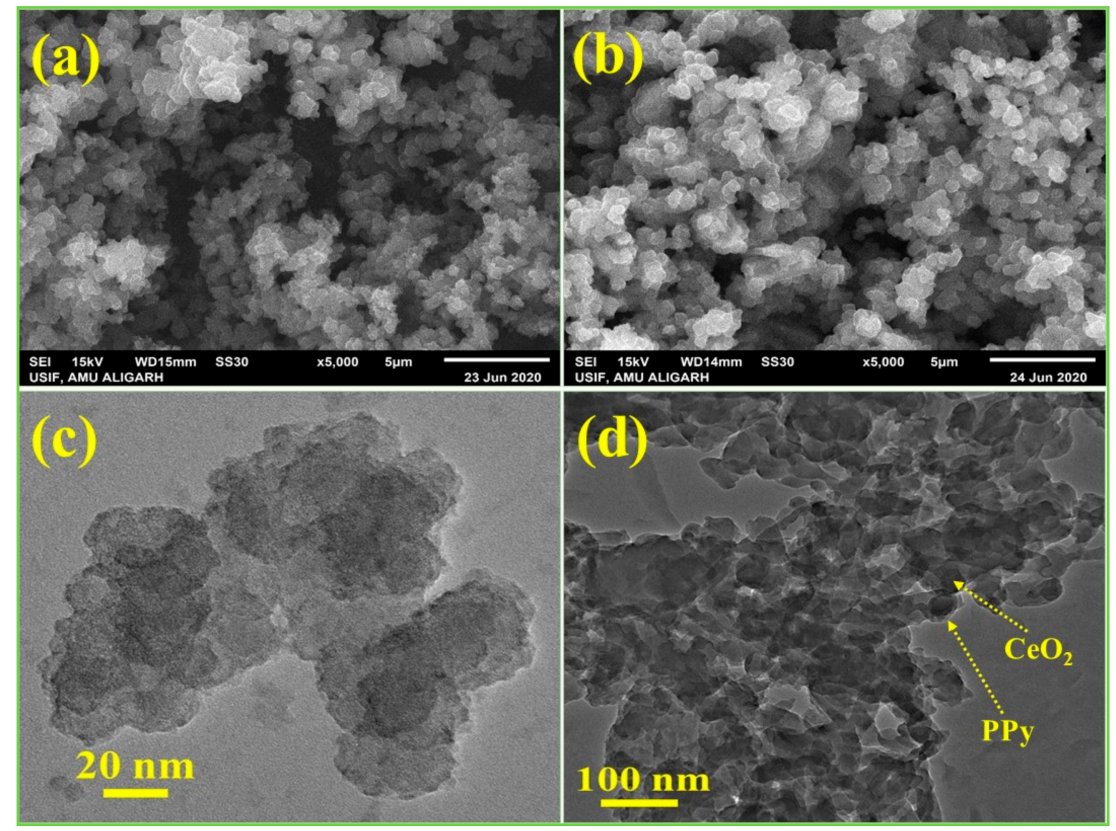

Figure 4. SEM and TEM images of PPy $(\mathbf{a}, \mathbf{c})$ and $\mathrm{PPy} / \mathrm{CeO}_{2}(\mathbf{b}, \mathbf{d})$, respectively.

\subsection{Thermogravimetric Analysis (TGA)}

The TGA curve of PPy, $\mathrm{CeO}_{2} \mathrm{NPs}$, and $\mathrm{PPy} / \mathrm{CeO}_{2}$ are displayed in Figure 5 . In the case of PPy (Figure 5a), the first weight loss at $85{ }^{\circ} \mathrm{C}$ is due to the loss of water in form of moisture. The observed subsequent regular weight loss at higher temperatures is related to dopant loss and degradation of the PPy matrix $[23,24]$. The total weight loss was found to be $92.649 \%$. 


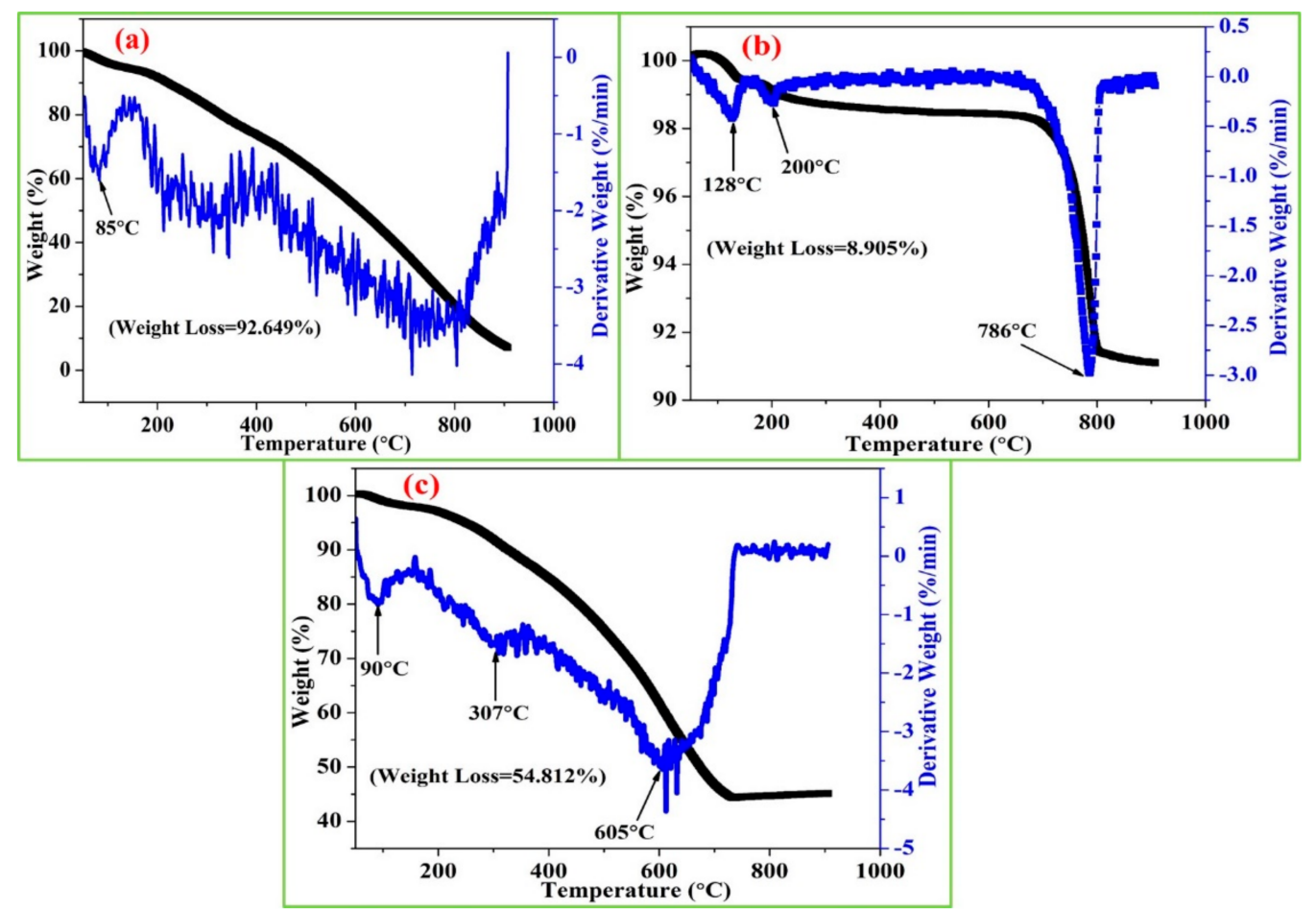

Figure 5. TGA curve of (a) $\mathrm{PPy},(\mathbf{b}) \mathrm{CeO}_{2} \mathrm{NPs}$, and (c) $\mathrm{PPy} / \mathrm{CeO}_{2}$.

In the case of $\mathrm{CeO}_{2} \mathrm{NPs}$ (Figure 5b), the total weight loss was found to be only $8.905 \%$ which shows outstanding stability. Thus, the incorporation of $\mathrm{CeO}_{2} \mathrm{NPs}$ into the PPy matrix proved to be very effective for increasing the thermal stability of $\mathrm{PPy} / \mathrm{CeO}_{2}$ as evident from Figure 5c. For PPy $/ \mathrm{CeO}_{2}$, weight loss at 90,307 , and $605{ }^{\circ} \mathrm{C}$ is caused by the loss of water, removal of dopant and degradation of PPy matrix. The total weight loss was found to be $54.812 \%$ which is very less as compared to pristine PPy $(92.649 \%)$. Thus, extra stability of $\mathrm{PPy} / \mathrm{CeO}_{2}$ also confirms the formulation of nanocomposite due to some interaction between PPy chains and $\mathrm{CeO}_{2} \mathrm{NPs}$ at molecular levels. The greater conductivity retention of $\mathrm{PPy} / \mathrm{CeO}_{2}$ than pristine PPy is due to greater thermal stability. This facilitates $\mathrm{PPy} / \mathrm{CeO}_{2}$ as the potential material for electrical conductor applications working above room temperature.

\subsection{Electrical Conductivity Studies}

Initial electrical conductivity (at $29{ }^{\circ} \mathrm{C}$ and $44 \%$ humidity) of PPy and $\mathrm{PPy} / \mathrm{CeO}_{2}$ was found to be $0.152 \mathrm{Scm}^{-1}$ and $1.295 \mathrm{Scm}^{-1}$, respectively (Figure 6a). The combination of $\mathrm{CeO}_{2} \mathrm{NPs}$ with PPy matrix increased the conductivity about 8.5 times than pristine PPy. The charge carriers of PPy and $\mathrm{PPy} / \mathrm{CeO}_{2}$ along with possible interaction of PPy chains with $\mathrm{CeO}_{2} \mathrm{NPs}$ are presented in Figure 6b, c, respectively. In the case of conducting polymer, the charge carriers (polarons and bipolarons) are very similar to holes as in semiconducting materials. The electrical conductivity is explained by both the quantity and mobility of these charge carriers. Thus, the electrical conductivity can be controlled and tuned by any interaction that can change the quantity and mobility of charge carriers. Consequently, the electrical conductivity can precisely be tuned by changing both the type and level of oxidation as well as the types and amount of filler components [23,24,40-44]. In conducting polymer-nanocomposites, the mechanism of conductivity is described by the movement of charge carriers along with the extended $\pi$-conjugated system of polymer backbone or/and the hopping/tunnelling between fillers and polymer chains [23,43,48,49]. Pristine conducting polymers act as good semiconductor at room temperature. However, at the higher temperature, their conductivity decreases even sometimes completely lost due to degradation of the polymer backbone. However, their nanocomposites act as good semiconductor/conductor even at elevated temperatures due to greater thermal 
stability imparted by nanofillers, better polymer chain alignment and enhancement in the $\pi$-conjugated system provided by synergistic/electronic interaction between polymer chains and filler inorganic nanoparticles at molecular levels [48,49].
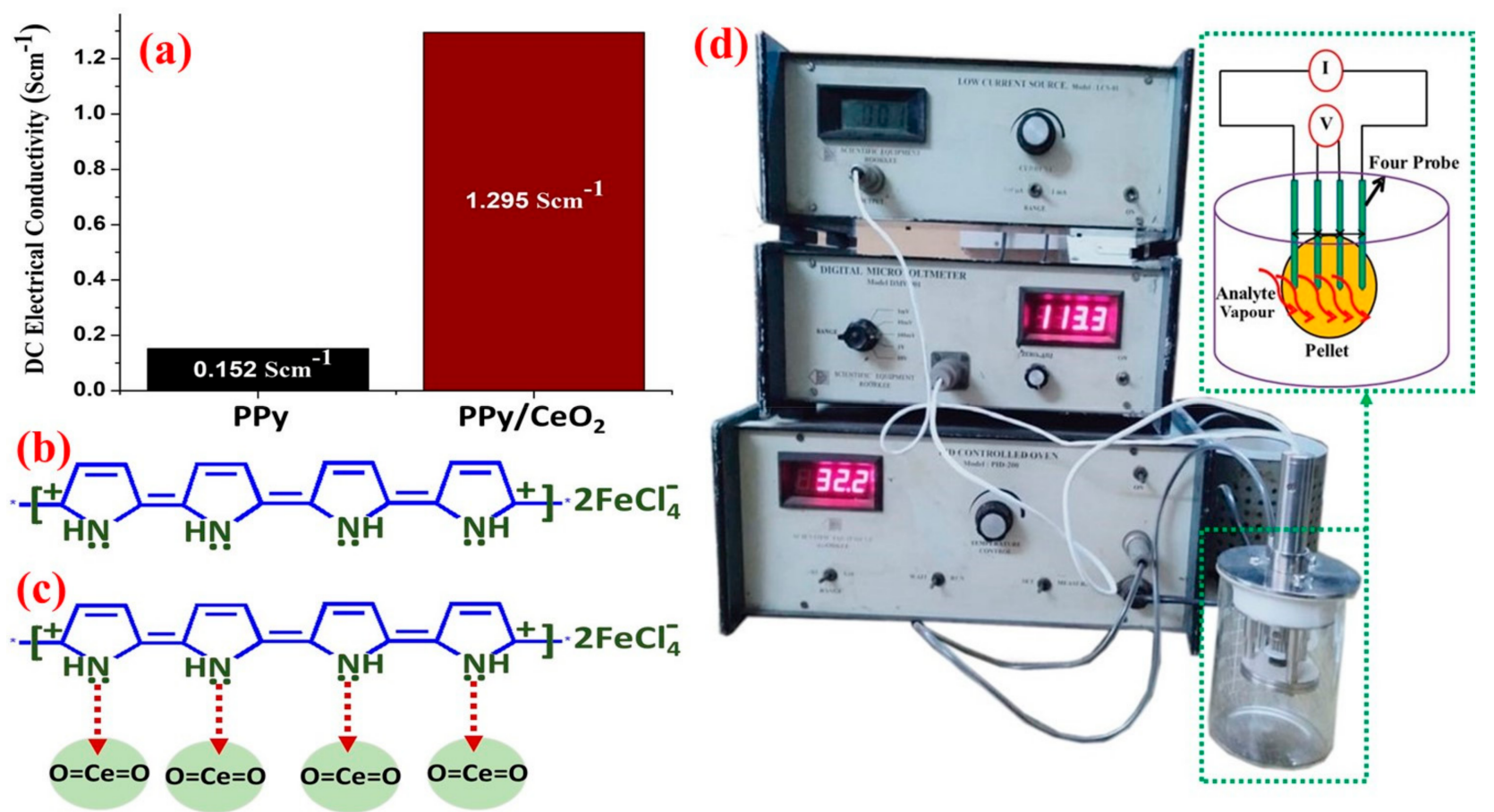

Figure 6. Initial conductivity of: (a) PPy and $\mathrm{PPy} / \mathrm{CeO}_{2}$, (b) charge carriers of PPy generated due to oxidation/doping, (c) the interaction of PPy chain with $\mathrm{CeO}_{2}$ NPs leading to the formation of more efficient electronic paths needed for conductivity enhancement, and (d) instrumental setup used in conductivity and sensing experiments.

Herein, we explained significant improvement in the conductivity of $\mathrm{PPy} / \mathrm{CeO}_{2}$ as compared to pristine PPy as follows: (1) The $\mathrm{CeO}_{2} \mathrm{NPs}$ make available a large surface area for the polymerization of pyrrole, thus generating a more efficient and extended $\pi$-conjugated system for charge carries transportation as compared to pristine PPy. (2) The possible electronic interaction of lone pairs of nitrogen atoms of PPy with cerium $\left(\mathrm{Ce}^{+4}\right)$ ions as well as highly electronegative oxygen atoms of $\mathrm{CeO}_{2} \mathrm{NPs}$ may increase the number of charge carriers. (3) Reduction in hopping/tunnelling distance between metallic regions and improved density of charge carriers.

\subsubsection{Electrical Conductivity Retention under Isothermal Ageing Condition}

The thermal stability of PPy and PPy/ $\mathrm{CeO}_{2}$ was determined by the conductivity retention under isothermal ageing conditions. We used the following equation to calculate relative conductivity $\left(\sigma_{r, t}\right)$ at a particular temperature

$$
\sigma_{r, t}=\frac{\sigma_{t}}{\sigma_{0}}
$$

where $\sigma_{t}$ and $\sigma_{0}$ denote the DC electrical conductivity $\left(\mathrm{Scm}^{-1}\right)$ at time $\mathrm{t}$ and zero, respectively $[43,44]$.

The pristine PPy showed good conductivity retention ability at $50{ }^{\circ} \mathrm{C}$ and $70{ }^{\circ} \mathrm{C}$. At $90{ }^{\circ} \mathrm{C}$, the conductivity was stable upto $10 \mathrm{~min}$ only, then it started to decrease slightly. However, at higher temperatures $\left(110{ }^{\circ} \mathrm{C}\right.$ and $\left.130{ }^{\circ} \mathrm{C}\right)$, the conductivity continuously decreased with respect to time which may be due to loss of moisture, dopant as well as the collapse of the $\pi$-conjugated system of the PPy chain (Figure 7) $[23,24,48,49]$. 

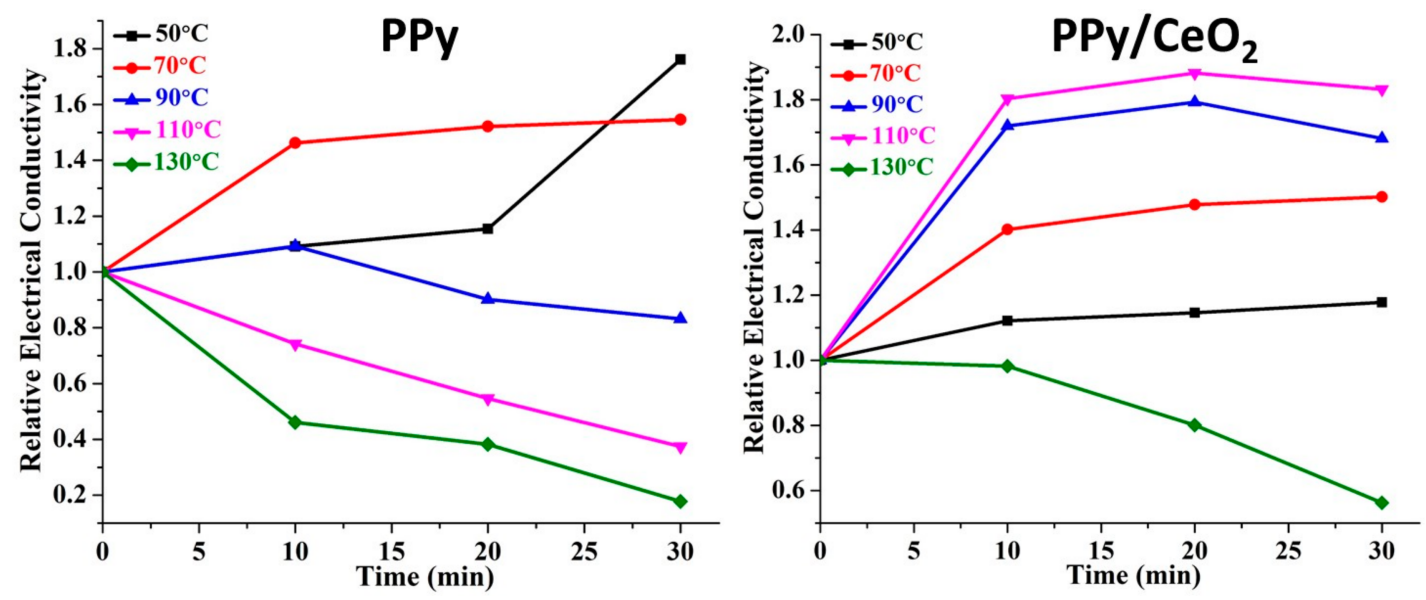

Figure 7. Relative electrical conductivity of $\mathrm{PPy}$ and $\mathrm{PPy} / \mathrm{CeO}_{2}$ with respect to time.

However, $\mathrm{PPy} / \mathrm{CeO}_{2}$ displayed much-improved conductivity retention ability as compared to PPy due to greater thermal stability (Figure 7). The conductivity of $\mathrm{PPy} / \mathrm{CeO}_{2}$ increased with increasing temperature showing good semiconducting nature at 50, 70, 90 , and $110^{\circ} \mathrm{C}$. Also, $\mathrm{PPy} / \mathrm{CeO}_{2}$ excellently retained its conductivity at $50{ }^{\circ} \mathrm{C}$ and $70{ }^{\circ} \mathrm{C}$. At $90^{\circ} \mathrm{C}$ and $110^{\circ} \mathrm{C}$, the conductivity was retained till $20 \mathrm{~min}$, after that slight decrease in conductivity was observed with respect to time. At $130{ }^{\circ} \mathrm{C}$, a sudden decrease in conductivity was detected be owing to loss of dopant plus degradation of PPy matrix.

\subsubsection{Electrical Conductivity Retention under Cyclic Ageing Condition}

The thermal stability of PPy and $\mathrm{PPy} / \mathrm{CeO}_{2}$ in terms of conductivity retention was also investigated under cyclic ageing conditions. The following equation was used for calculation of relative electrical conductivity $\left(\sigma_{\mathrm{r}}\right)$

$$
\sigma=\frac{\sigma_{T}}{\sigma_{50}}
$$

where $\sigma_{\mathrm{T}}$ and $\sigma_{50}$ correspond to the DC electrical conductivity at temperature $\mathrm{T}\left({ }^{\circ} \mathrm{C}\right)$ and $50{ }^{\circ} \mathrm{C}$, respectively [43,44].

PPy exhibited good semiconducting properties, i.e., increase in conductivity with increasing temperature for only one cycles (Figure 8 ). In the second cycle, conductivity increased only up to $70^{\circ} \mathrm{C}$; after that, a slight decline was observed. For the third and fourth cycle, conductivity decreased continuously with increasing temperature due to loss of dopant as well as degradation of PPy [23,24]. However, $\mathrm{PPy} / \mathrm{CeO}_{2}$ showed better stability as compared to pristine PPy. PPy $/ \mathrm{CeO}_{2}$ was found to be stable in all four cycles. $\mathrm{PPy} / \mathrm{CeO}_{2}$ showed the gain in conductivity for all four cycles which may be due to greater mobility of charge carriers at elevated temperatures (Figure 8). However, gain in conductivity in the first cycle was not as much as all three following cycles. Most importantly, for the second, third, and fourth cycles, the gain in conductivity showed an almost similar trend showing good conductivity retention ability of $\mathrm{PPy} / \mathrm{CeO}_{2}$.

Thus, $\mathrm{PPy} / \mathrm{CeO}_{2}$ displayed significantly improved electrical properties as compared to pristine PPy in terms of initial conductivity and conductivity retention under isothermal as well as cyclic ageing condition. 



Figure 8. Relative electrical conductivity of $\mathrm{PPy}$ and $\mathrm{PPy} / \mathrm{CeO}_{2}$ at different temperatures.

\subsection{Ammonia Vapor Sensing Studies}

Ammonia vapor sensing characteristics PPy and $\mathrm{PPy} / \mathrm{CeO}_{2}$ sensor pellets were evaluated in terms of various parameters, for example, \% sensing response, response time, recovery time, reversibility, selectivity, and stability at room temperature. In the end, a sensing mechanism was also proposed. To determine the effect of ammonia vapors on the electrical conductivity of sensors, first of all, the selected sensor pellet was firmly connected with the probe of the device. Then, it was kept in a closed chamber containing ammonia solutions of known concentration (Figure 6d). The pellet was exposed in ammonia vapor for $200 \mathrm{~s}$ for the adsorption of ammonia molecules on the sensor surface and variation in the conductivity was recorded. After that, the sensor pellet was removed from the chamber and kept in the ambient air for $200 \mathrm{~s}$. A sudden and regular decrease in the sensor's conductivity was detected in ammonia vapor, which became constant after some time. Whereas in the air, the conductivity of the sensor started to increase and became saturated (Figure 9). The \% sensing response of $\mathrm{PPy}$ and $\mathrm{PPy} / \mathrm{CeO}_{2}$ based sensors was evaluated by employing the formula

$$
S=\frac{\Delta \sigma}{\sigma_{i}} \times 100
$$

where $\sigma_{\mathrm{i}}$ and $\Delta \sigma$ correspond to the initial DC electrical conductivity and change in the conductivity of sensor-pellets in the ammonia vapor for $200 \mathrm{~s}$, respectively [21,40,42].

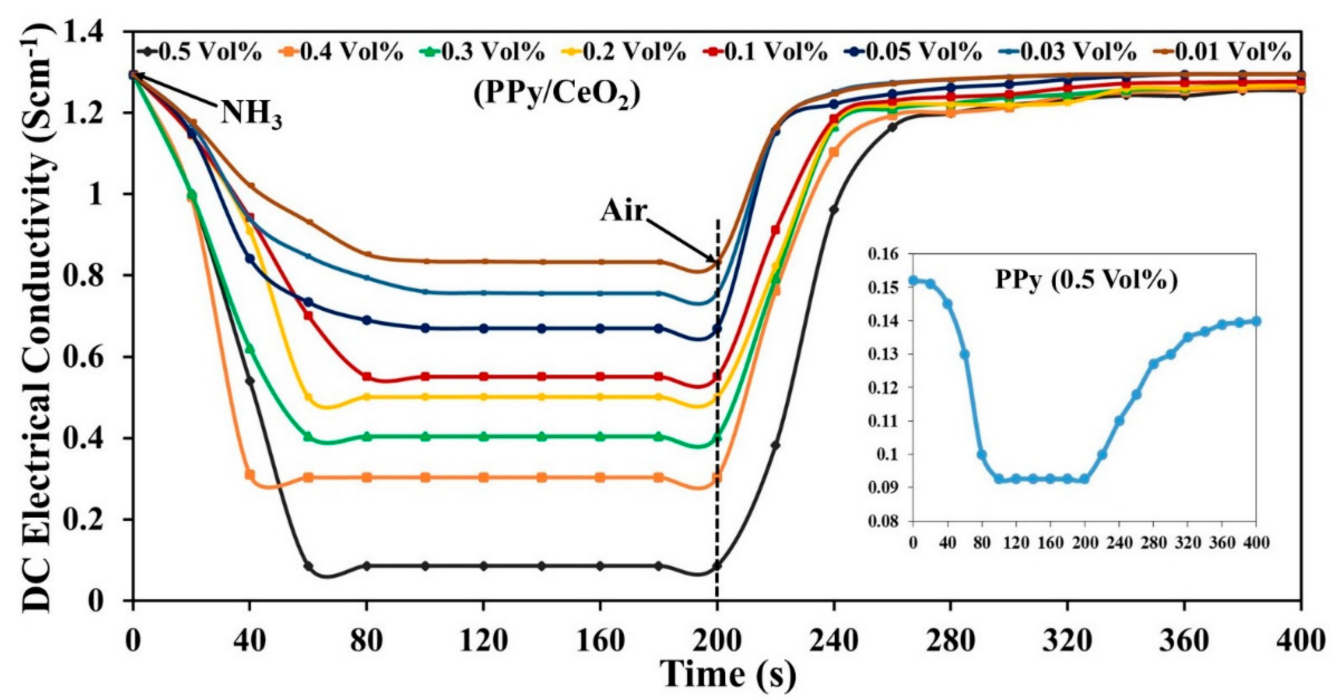

Figure 9. Change in conductivity of PPy $/ \mathrm{CeO}_{2}$ and PPy (inset) sensors in ammonia vapor and air with respect to time. 


\subsubsection{Sensing Response}

The \% sensing response of PPy and $\mathrm{PPy} / \mathrm{CeO}_{2}$ sensors towards ammonia vapor was calculated at $0.5 \mathrm{vol} \%$ concentration of ammonia solution and found to be $39.1 \%$ and $93.4 \%$, respectively. Herein, the response time and recovery times are defined as the times required to reach $90 \%$ of the total conductivity change.

The response and recovery time for the PPy sensor at $0.5 \mathrm{vol} \%$ ammonia concentration was found to be about $80 \mathrm{~s}$ and $150 \mathrm{~s}$, respectively. However, response and recovery time for PPy $/ \mathrm{CeO}_{2}$ based sensor $0.5 \mathrm{vol} \%$ ammonia concentration was found to be about $40 \mathrm{~s}$ and $60 \mathrm{~s}$, respectively. Thus, the $\mathrm{PPy} / \mathrm{CeO}_{2}$ based sensor showed a much greater \% sensing response and shorter response/recovery time as compared to the sensor based on pristine PPy. Therefore, \% sensing response and response/recovery time PPy $/ \mathrm{CeO}_{2}$ sensor was also calculated at $0.4,0.3,0.2,0.1,0.05,0.03$, and $0.01 \mathrm{vol} \%$ ammonia concentrations and found to be $76.2 \%, 68.8 \%, 61.4 \%, 57.5 \%, 48.2 \%, 41.6 \%$, and $35.6 \%$, respectively (Figure $10 \mathrm{a}$ ). The response and recovery time was also affected significantly as ammonia concentration changes. The response/recovery time was found to be $45 \mathrm{~s} / 47 \mathrm{~s}, 52 \mathrm{~s} / 40 \mathrm{~s}, 56 \mathrm{~s} / 38 \mathrm{~s}$, $59 \mathrm{~s} / 30 \mathrm{~s}, 65 \mathrm{~s} / 26 \mathrm{~s}, 69 \mathrm{~s} / 23 \mathrm{~s}$, and $75 \mathrm{~s} / 20 \mathrm{~s}$ at $0.4,0.3,0.2,0.1,0.05,0.03$, and $0.01 \mathrm{vol} \%$ ammonia concentrations, respectively (Figure 10b).


Figure 10. (a) Variation in \% sensing response and (b) response and recovery time of $\mathrm{PPy} / \mathrm{CeO}_{2}$ sensor with respect to the different ammonia concentration.

\subsubsection{Reversibility}

To determine the reproducibility of the sensor, the selected sensor pellet was exposed alternately in ammonia vapor for the $30 \mathrm{~s}$ and air for $30 \mathrm{~s}$ to complete one cycle, and the change in conductivity was recorded. This experiment was performed for five succeeding cycles comprising a total of $180 \mathrm{~s}$. The reversibility of the sensor was described in terms of $\%$ recovery of its initial conductivity (i.e., conductivity at zero time) after completion of the fifth cycle. For the PPy sensor at $0.5 \mathrm{vol} \%$, there was a regular decrease in the conductivity after each cycle. Therefore, conductivity could not return to its original value (Figure 11). The reversibility of PPy at $0.5 \mathrm{vol} \%$ was found to be $72.4 \%$ because of very slow and partial desorption of ammonia molecules. However, the $\mathrm{PPy} / \mathrm{CeO}_{2}$ based sensor exhibited much higher reversibility than PPy sensor. $\mathrm{PPy} / \mathrm{CeO}_{2}$ based sensor showed an excellent dynamic response of electrical conductivity in ammonia vapor and ambient air (Figure 12). The reversibility of $\mathrm{PPy} / \mathrm{CeO}_{2}$ based sensor at $0.5,0.4,0.3,0.2,0.1,0.05,0.03$, and $0.01 \mathrm{vol} \%$ was found to be $90.6 \%, 91.4 \%, 94.6 \%, 95.3 \%, 96.1 \%, 98.2 \%, 98.9 \%$, and $99.3 \%$, respectively. The excellent reversibility of the $\mathrm{PPy} / \mathrm{CeO}_{2}$ based sensor may be attributed to the quick and nearly complete desorption of ammonia molecules from its surface. 


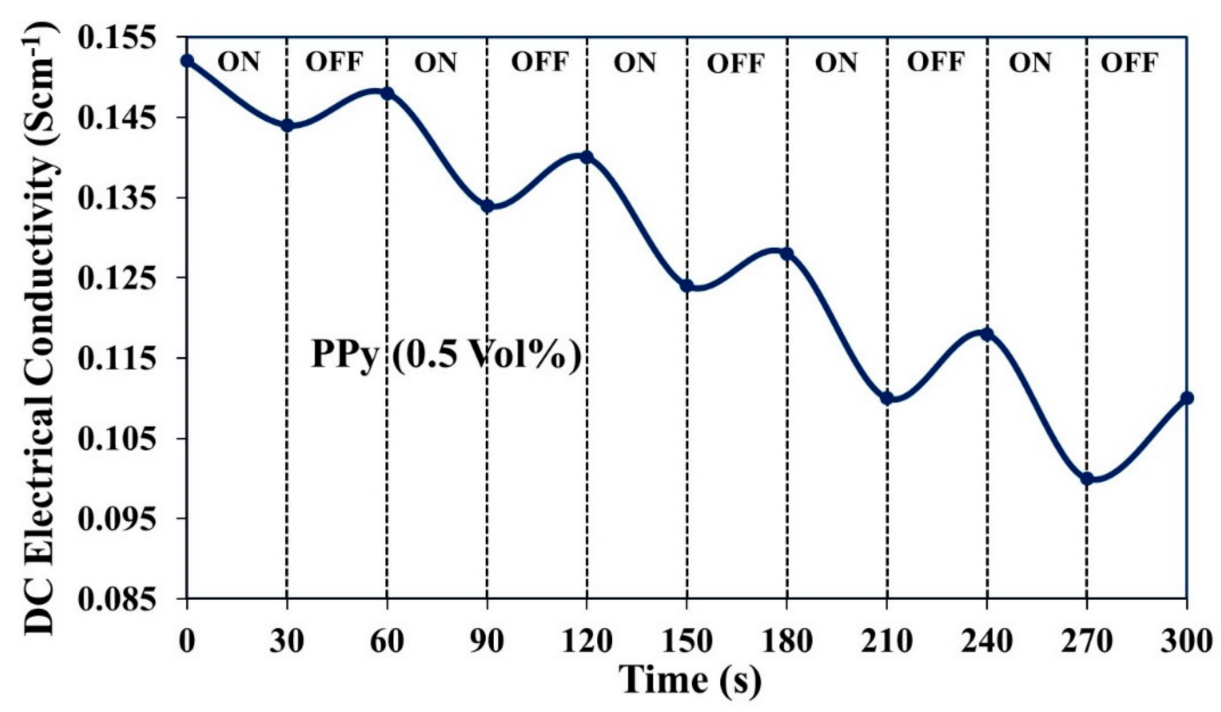

Figure 11. Reversibility of PPy based sensor at $0.5 \mathrm{vol} \%$ ammonia concentrations.



Figure 12. Reversibility of $\mathrm{PPy} / \mathrm{CeO}_{2}$ based sensor at various ammonia concentrations.

\subsubsection{Selectivity}

To determine the selectivity of the $\mathrm{PPy} / \mathrm{CeO}_{2}$ based sensor towards ammonia vapor at $0.5 \mathrm{vol} \%$ and $0.01 \mathrm{vol} \%$, its sensing response was also calculated in the presence of several other volatile organic compounds (VOCs). The \% sensing response was calculated at $0.5 \mathrm{vol} \%$ concentration of ethanol, methanol, acetone, acetaldehyde, formaldehyde. Whereas toluene, benzene, chloroform, and $n$-hexane were utilized as received in the experiment. The $\%$ sensing response was found to $93.4 \%, 33.1 \%, 29.3 \%, 17.9 \%, 15.4 \%, 12.6 \%$, $10.5 \%, 8.8 \%, 8.1 \%$, and $5.8 \%$ towards ammonia, ethanol, methanol, acetone, acetaldehyde, formaldehyde, toluene, benzene, chloroform, and $n$-hexane, respectively (Figure 13a). Whereas, at $0.01 \mathrm{vol} \%$, the sensor only responded towards ammonia vapors which showed that sensor was exclusively selective for ammonia (Figure 13a). Due to different electrondonating tendency as well as the rate of vaporization, all the tested VOCs here adsorbed to a different extent on the sensor-surface. Therefore, they interact differently with charge carriers and hence showed varying sensing response. Among all VOCs here, ammonia has the greatest electron-donating tendency along with a very high evaporation rate. Therefore, it neutralizes a large number of charge carriers which significantly reduce charge density and ultimately triggering the highest decrease in conductivity as compared to other VOCs. Thus, the $\mathrm{PPy} / \mathrm{CeO}_{2}$ based sensor displayed outstanding selectivity to ammonia vapor as compared to different VOCs tested. 

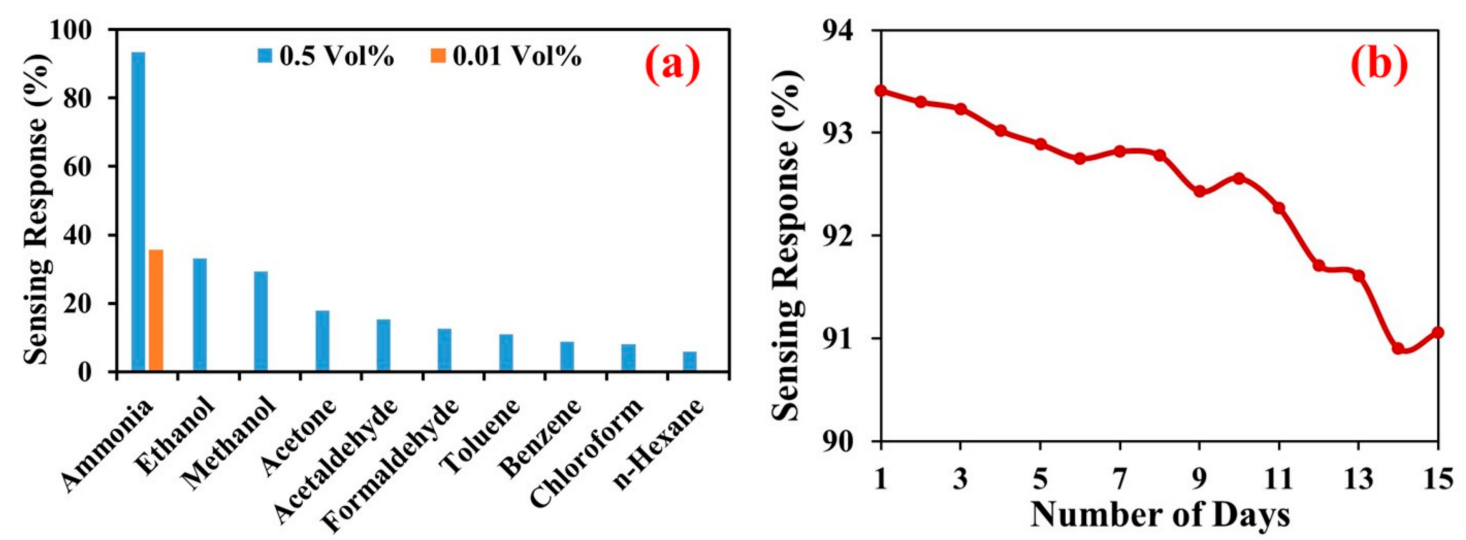

Figure 13. (a) Selectivity of $\mathrm{PPy} / \mathrm{CeO}_{2}$ based sensor at $0.5 \mathrm{vol} \%$ ammonia concentrations against different VOCs and (b) stability of $\mathrm{PPy} / \mathrm{CeO}_{2}$ sensor.

\subsubsection{Stability}

The stability of $\mathrm{PPy} / \mathrm{CeO}_{2}$ based sensor is evaluated by recording its \% sensing response for 15 successive days. The \% sensing response was calculated for successive 15 days at $0.5 \mathrm{vol} \%$ and found to $93.40 \%, 93.30 \%, 93.23 \%, 93.02 \%, 92.89 \%, 92.75 \%, 92.82 \%$, $92.78 \%, 92.43 \%, 92.56 \%, 92.27 \%, 91.71 \%, 91.61 \%, 90.90 \%$, and 91.06\%, respectively (Figure 13b). Thus, after 15 days, its sensing response was decreased from $93.40 \%$ to $91.06 \%$ which indicate outstanding stability.

\subsubsection{Sensing Mechanism}

The vapor/gas sensing mechanism of conducting-polymer-based sensors depend on the rate of adsorption-desorption of analyte molecules on the sensor-surface [50,51]. The adsorbed vapor/gas molecules, then interact electronically with the charge carriers. Consequently, the sensor's electrical conductivity/resistance changes depending upon the type of vapor/gas. The electron donor species (i.e., reducing gas/vapor), for example, ammonia, reduces the charge carrier density, which causes a decrease in conductivity. When the sensor is detached from the vapor/gas' atmosphere and exposed in air, the analyte molecules start to desorb, and interaction of analyte molecules with charge carriers decreases. Thus, the sensor's electrical conductivity starts to increase with the increasing rate of desorption [40-44,50,51]. The sensor's response/recovery time significantly depend on the rate of adsorption and desorption. The greater the sensor's surface area, greater will be the number of active sites and hence greater will be the rate of adsorption. Therefore, the improved performance of the $\mathrm{PPy} / \mathrm{CeO}_{2}$ based sensor may be related to the greater surface area provided by $\mathrm{CeO}_{2} \mathrm{NPs}$, which enabled a larger number of active sites for the adsorption of ammonia molecules (Figure 14).

The number of ammonia molecules increases on increasing concentration, which ultimately interact with a much greater number of charge carriers and reduced the density of charge carriers much faster than at lower concentrations. Hence, at higher concentrations, the $\%$ sensing response was greater along with a shorter response time. However, recovery time at higher concentrations are larger than those at lower concentration because, at higher concentrations, a large number of ammonia molecules need to be desorbed, which take a longer time (Table 2). The greater \% sensing response and shorter response/recovery time of sensors based on PPy $/ \mathrm{CeO}_{2}$ than PPy sensor also revealed the possibility of more rapid adsorption and desorption process of ammonia molecules on $\mathrm{PPy} / \mathrm{CeO}_{2}$ sensor pellet as compared to PPy. 


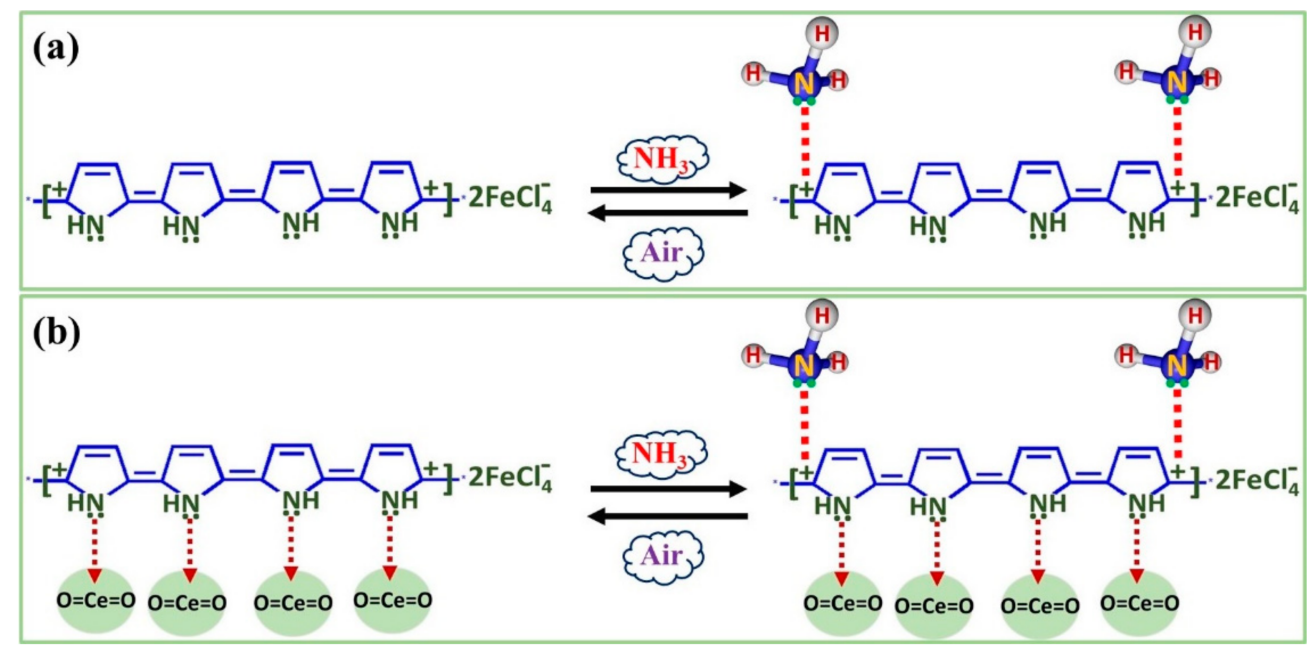

Figure 14. Proposed ammonia vapor sensing mechanism is showing the electronic interaction of ammonia molecules with the charge carriers of: (a) $\mathrm{PPy}$ and (b) $\mathrm{PPy} / \mathrm{CeO}_{2}$ based sensor pellets.

Table 2. Summarized results of $\mathrm{PPy} / \mathrm{CeO}_{2}$ based sensor pellet towards different concentrations of ammonia vapor.

\begin{tabular}{cccccc}
\hline S. No. & $\begin{array}{c}\text { Ammonia- } \\
\text { Concentration (vol \%) }\end{array}$ & $\begin{array}{c}\text { Sensing } \\
\text { Response (\%) }\end{array}$ & $\begin{array}{c}\text { Response } \\
\text { Time (s) }\end{array}$ & $\begin{array}{c}\text { Recovery } \\
\text { Time (s) }\end{array}$ & $\begin{array}{c}\text { Reversibility } \\
\text { (\%) }\end{array}$ \\
\hline 1. & 0.5 & 93.4 & 40 & 60 & 90.6 \\
\hline 2. & 0.4 & 76.2 & 45 & 47 & 91.4 \\
\hline 3. & 0.3 & 68.8 & 52 & 40 & 94.6 \\
\hline 4. & 0.2 & 61.4 & 56 & 38 & 95.3 \\
\hline 5. & 0.1 & 57.5 & 59 & 30 & 96.1 \\
\hline 6. & 0.05 & 48.2 & 65 & 26 & 98.2 \\
\hline 7. & 0.03 & 41.6 & 69 & 23 & 98.9 \\
\hline 8. & 0.01 & 35.6 & 75 & 20 & 99.3 \\
\hline
\end{tabular}

A comparison of sensing parameters of this $\mathrm{PPy} / \mathrm{CeO}_{2}$ sensor with the previously published ammonia sensing studies on PPy based sensors are given in Table 3.

Table 3. Comparison of present study with the other ammonia sensors based on PPy.

\begin{tabular}{|c|c|c|c|c|c|c|}
\hline S. No. & Material Used & $\begin{array}{l}\text { Method of } \\
\text { Preparation }\end{array}$ & Response (\%) & Response Time & Recovery Time & Reference \\
\hline 1. & PPy/RGO & $\begin{array}{l}\text { Chemical } \\
\text { oxidative }\end{array}$ & 50 at $10 \mathrm{ppm}$ & $200 \mathrm{~s}$ & $90 \mathrm{~s}$ & [1] \\
\hline 2. & $\mathrm{SnO}_{2} / \mathrm{ZnO} / \mathrm{PPy}$ & $\begin{array}{l}\text { Electro-spinning } \\
\text { method }\end{array}$ & 0.68 at $30 \mathrm{ppm}$ & $67 \mathrm{~s}$ & $106 \mathrm{~s}$ & [2] \\
\hline 3. & PPy thin films & Solution casting & 12 at $25 \mathrm{ppm}$ & $90 \mathrm{~s}$ & $10 \mathrm{~min}$ & [3] \\
\hline 4. & $\mathrm{PPy} / \mathrm{Au}$ & $\begin{array}{l}\text { Chemical } \\
\text { oxidative }\end{array}$ & 50 at $300 \mathrm{ppm}$ & $40 \mathrm{~s}$ & $80 \mathrm{~s}$ & [4] \\
\hline 5. & $\mathrm{PPy} / \mathrm{Zn}_{2} \mathrm{SnO}_{4}$ & $\begin{array}{l}\text { Layer-by-layer } \\
\text { self-assembly }\end{array}$ & 82.1 at $100 \mathrm{ppm}$ & $35 \mathrm{~s}$ & $26 s$ & [5] \\
\hline 6. & $\mathrm{PPy} / \mathrm{MoS}_{2}$ & $\begin{array}{l}\text { Chemical } \\
\text { oxidative }\end{array}$ & - & $60 s$ & $50 \mathrm{~s}$ & [17] \\
\hline 7. & $\mathrm{PPy} / \mathrm{CeO}_{2}$ & $\begin{array}{l}\text { Chemical } \\
\text { oxidative }\end{array}$ & $\begin{array}{c}93.4 \text { at } 0.5 \mathrm{vol} \% \text { and } \\
35.6 \text { at } 0.01 \mathrm{vol} \%\end{array}$ & $\begin{array}{c}40 \mathrm{~s} \text { at } 0.5 \mathrm{vol} \% \text { and } \\
75 \mathrm{~s} \text { at } 0.01 \mathrm{vol} \%\end{array}$ & $\begin{array}{l}60 \mathrm{~s} \text { at } 0.5 \mathrm{vol} \% \\
\text { and } 19 \mathrm{~s} \text { at } 0.01\end{array}$ & This study \\
\hline
\end{tabular}




\section{Conclusions}

We report the preparation and characterization of polypyrrole (PPy) and polypyrrole/cerium oxide ( $\mathrm{PPy} / \mathrm{CeO}_{2}$ ) nanocomposites for the fabrication of a promising pelletshaped ammonia vapor sensor. DC electrical conductivities of PPy and PPy $/ \mathrm{CeO}_{2}$ were found to be $0.152 \mathrm{Scm}^{-1}$ and $1.295 \mathrm{Scm}^{-1}$, respectively at room temperature. $\mathrm{PPy} / \mathrm{CeO}_{2}$ nanocomposite showed much greater conductivity retention properties than PPy under both the isothermal and cyclic ageing conditions. $\mathrm{PPy} / \mathrm{CeO}_{2}$ sensor exhibit much higher sensing performance than pristine PPy sensor at $0.5 \mathrm{vol} \%$ ammonia concentration in terms of $\%$ sensing response, response/recovery time and reversibility. The sensing performance of the PPy $/ \mathrm{CeO}_{2}$ sensor at room temperature was also studied at 0.4. 0.3, 0.2, 0.1, 0.05, 0.03, and $0.01 \mathrm{vol} \%$ ammonia concentration in terms of $\%$ sensing response, response/recovery time, reversibility, selectivity and stability. The response and recovery time for the PPy sensor at $0.5 \mathrm{vol} \%$ ammonia concentration was found to be about $80 \mathrm{~s} / 150 \mathrm{~s}$, respectively. However, response/recovery time for $\mathrm{PPy} / \mathrm{CeO}_{2}$ based sensor $0.5 \mathrm{vol} \%$ ammonia concentration was found to be about $40 \mathrm{~s} / 60 \mathrm{~s}$, respectively. The \% sensing response of $\mathrm{PPy} / \mathrm{CeO}_{2}$ sensor was also calculated at $0.4,0.3,0.2,0.1,0.05,0.03$, and $0.01 \mathrm{vol} \%$ ammonia concentrations and found to be $76.2 \%, 68.8 \%, 61.4 \%, 57.5 \%, 48.2 \%, 41.6 \%$, and $35.6 \%$, respectively. The response and recovery time of the $\mathrm{PPy} / \mathrm{CeO}_{2}$ sensor varies significantly as ammonia concentration changes from $0.01 \mathrm{vol} \%$ to $0.5 \mathrm{vol} \%$. The response/recovery time was found to be $45 \mathrm{~s} / 47 \mathrm{~s}, 52 \mathrm{~s} / 40 \mathrm{~s}, 56 \mathrm{~s} / 38 \mathrm{~s}, 59 \mathrm{~s} / 30 \mathrm{~s}, 65 \mathrm{~s} / 26 \mathrm{~s}, 69 \mathrm{~s} / 23 \mathrm{~s}$, and $75 \mathrm{~s} / 20 \mathrm{~s}$ at $0.4,0.3$, $0.2,0.1,0.05,0.03$, and $0.01 \mathrm{vol} \%$ ammonia concentrations, respectively. The reversibility of $\mathrm{PPy} / \mathrm{CeO}_{2}$ sensor at $0.5,0.4,0.3,0.2,0.1,0.05,0.03$, and $0.01 \mathrm{vol} \%$ was found to be $90.6 \%$, $91.4 \%, 94.6 \%, 95.3 \%, 96.1 \%, 98.2 \%, 98.9 \%$, and $99.3 \%$, respectively along with exceptional selectivity towards ammonia vapor.

Author Contributions: Conceptualization, A.H., I.K. and M.M.A.K.; methodology, A.K.; formal analysis, M.A.H.; investigation, A.M.A. (Abeer Mohamed Alosaimi); resources, A.M.A. (Abdullah M. Asiri). S.A.A.-Z., A.A.O., M.J. makes data calculation. All authors have read and agreed to the published version of the manuscript.

Funding: This research was funded by Taif University, (grant no. TURSP-2020/244), and the APC was funded by University Putra Malaysia.

Institutional Review Board Statement: Not applicable.

Informed Consent Statement: Not applicable.

Data Availability Statement: The data presented in this study are available on request from the corresponding author.

Acknowledgments: Taif University Researchers Supporting Project (no. TURSP-2020/244), Taif University, Taif, Saudi Arabia.

Conflicts of Interest: The authors declare no conflict of interest.

\section{References}

1. Sun, J.; Shu, X.; Tian, Y.; Tong, Z.; Bai, S.; Luo, R.; Li, D.; Liu, C.C. Facile preparation of polypyrrole-reduced graphene oxide hybrid for enhancing NH3 sensing at room temperature. Sens. Actuators B Chem. 2017, 241, 658-664. [CrossRef]

2. Lamdhade, G.T.; Raulkar, K.B.; Yawale, S.S.; Yawale, S.P. Fabrication of multilayer $\mathrm{SnO}_{2}-\mathrm{ZnO}-\mathrm{PPy}$ sensor for ammonia gas detection. Indian J. Phys. 2015, 89, 1025-1030. [CrossRef]

3. Joshi, A.; Gangal, S.A.; Gupta, S.K. Ammonia sensing properties of polypyrrole thin films at room temperature. Sens. Actuators $B$ Chem. 2011, 156, 938-942. [CrossRef]

4. Zhang, J.; Liu, X.; Wu, S.; Xu, H.; Cao, B. One-pot fabrication of uniform polypyrrole/Au nanocomposites and investigation for gas sensing. Sens. Actuators B Chem. 2013, 186, 695-700. [CrossRef]

5. Zhang, D.; Wu, Z.; Zong, X.; Zhang, Y. Fabrication of Polypyrrole/ $\mathrm{Zn}_{2} \mathrm{SnO}_{4}$ Nanofilm for Ultra-Highly Sensitive Ammonia Sensing Application. Sens. Actuators B Chem. 2018, 274, 575-586. [CrossRef]

6. Liu, B.; Liu, X.; Yuan, Z.; Jiang, Y.; Su, Y.; Ma, J.; Tai, H. A flexible $\mathrm{NO}_{2}$ gas sensor based on polypyrrole/nitrogen-doped multiwall carbon nanotube operating at room temperature. Sens. Actuators B Chem. 2019, 295, 86-92. [CrossRef] 
7. Tai, H.; Duan, Z.; He, Z.; Li, X.; Xu, J.; Liu, B.; Jiang, Y. Enhanced ammonia response of Ti3C2Tx nanosheets supported by TiO 2 nanoparticles at room temperature. Sens. Actuators B Chem. 2019, 298, 126874. [CrossRef]

8. Lefferts, M.J.; Humphreys, L.H.; Mai, N.; Murugappan, K.; Armitage, B.I.; Pons, J.F.; Castell, M.R. ANFO vapor detection with conducting polymer percolation network sensors and GC/MS. Analyst 2021, 146, 2186-2193. [CrossRef]

9. Armitage, B.I.; Murugappan, K.; Lefferts, M.J.; Cowsik, A.; Castell, M.R. Conducting polymer percolation gas sensor on a flexible substrate. J. Mater. Chem. C 2020, 8, 12669-12676. [CrossRef]

10. Oh, H.J.; Yeang, B.J.; Park, Y.K.; Choi, H.J.; Kim, J.H.; Kang, Y.S.; Bae, Y.; Kim, J.Y.; Lim, S.J.; Lee, W.; et al. Washable colorimetric nanofiber nonwoven for ammonia gas detection. Polymers 2020, 12, 1585. [CrossRef]

11. Park, Y.K.; Oh, H.J.; Bae, J.H.; Lim, J.Y.; Lee, H.D.; Hong, S.I.; Son, H.S.; Kim, J.H.; Lim, S.J.; Lee, W. Colorimetric textile sensor for the simultaneous detection of nh3 and hcl gases. Polymers 2020, 12, 2595. [CrossRef]

12. Ly, T.N.; Park, S. Highly sensitive ammonia sensor for diagnostic purpose using reduced graphene oxide and conductive polymer. Sci. Rep. 2018, 8, 1-12. [CrossRef]

13. Yin, Y.; Zhang, H.; Huang, P.; Xiang, C.; Zou, Y.; Xu, F.; Sun, L. Inducement of nanoscale Cu-BTC on nanocomposite of PPy-rGO and its performance in ammonia sensing. Mater. Res. Bull. 2018, 99, 152-160. [CrossRef]

14. Zhang, D.; Wu, Z.; Li, P.; Zong, X.; Dong, G.; Zhang, Y. Facile fabrication of polyaniline/multi-walled carbon nanotubes/molybdenum disulfide ternary nanocomposite and its high-performance ammonia-sensing at room temperature. Sens. Actuators B Chem. 2017, 258, 895-905. [CrossRef]

15. Qin, Y.; Zhang, B.; Zhang, Z. Combination of PPy with three-dimensional rGO to construct bioinspired nanocomposite for NH3-sensing enhancement. Org. Electron. 2019, 70, 240-245. [CrossRef]

16. van Hieu, N.; Quoc, N.; Dinh, P.; Trung, T.; Duc, N. Thin film polypyrrole/SWCNTs nanocomposites-based NH 3 sensor operated at room temperature. Sens. Actuators B Chem. 2009, 140, 500-507. [CrossRef]

17. Ahmad, S.; Khan, I.; Husain, A.; Khan, A.; Asiri, A.M. Electrical conductivity based ammonia sensing properties of polypyrrole/ $\mathrm{MoS}_{2}$ nanocomposite. Polymers 2020, 12, 3047. [CrossRef]

18. Sharma, S.; Hussain, S.; Singh, S.; Islam, S.S. MWCNT-conducting polymer composite based ammonia gas sensors: A new approach for complete recovery process. Sens. Actuators B Chem. 2014, 194, 213-219. [CrossRef]

19. Abdulla, S.; Mathew, T.L.; Pullithadathil, B. Highly sensitive, room temperature gas sensor based on polyaniline-multiwalled carbon nanotubes (PANI/MWCNTs) nanocomposite for trace-level ammonia detection. Sens. Actuators B Chem. 2015, 221, 1523-1534. [CrossRef]

20. Eising, M.; Cava, C.E.; Salvatierra, R.V.; Zarbin, A.J.; Roman, L.S. Doping effect on self-assembled films of polyaniline and carbon nanotube applied as ammonia gas sensor. Sens. Actuators B Chem. 2017, 245, 25-33. [CrossRef]

21. Husain, S.; Ahmad, S.; Mohammad, F. Electrical conductivity and ammonia sensing studies on polythiophene/MWCNTs nanocomposites. Materialia 2020, 14, 100868. [CrossRef]

22. Husain, A.; Ahmad, S.; Shariq, M.U.; Khan, M.M. Ultra-sensitive, highly selective and completely reversible ammonia sensor based on polythiophene/SWCNT nanocomposite. Materialia 2020, 10, 100704. [CrossRef]

23. Sultan, T.; Anwer, S.; Ahmad, F. Mohammad, preparation, characterization, and dynamic adsorption-Desorption studies on polypyrrole encapsulated $\mathrm{TiO}_{2}$ nanoparticles. J. Appl. Polym. Sci. 2016, 43411, 1-11. [CrossRef]

24. Sultan, S.; Ahmad, S.; Mohammad, F. Highly sensitive chlorine gas sensor and enhanced thermal DC electrical conductivity from polypyrrole/silicon carbide nanocomposites. RSC Adv. 2016, 6, 84200-84208. [CrossRef]

25. Barkade, S.S.; Pinjari, D.V.; Singh, A.K.; Gogate, P.R.; Naik, J.B.; Sonawane, S.H.; Ashokkumar, M.; Pandit, A.B. Ultrasound assisted miniemulsion polymerization for preparation of polypyrrole-Zinc Oxide (PPy/ZnO) functional latex for lique fi ed petroleum gas sensing. Ind. Eng. Chem. Res. 2013, 52, 7704-7712. [CrossRef]

26. Singh, K.; Nowotny, J.; Thangadurai, V. Amphoteric oxide semiconductors for energy conversion devices: A tutorial review. Chem. Soc. Rev. 2013, 42, 1961-1972. [CrossRef]

27. Nuraje, N.; Asmatulu, R.; Kudaibergenov, S. Metal oxide-based functional materials for solar energy conversion: A review. Curr. Inorg. Chem. 2012, 2, 124-146. [CrossRef]

28. Montemor, M.F.; Pinto, R.; Ferreira, M.G.S. Chemical composition and corrosion protection of silane films modified with $\mathrm{CeO}_{2}$ nanoparticles. Electrochim. Acta 2009, 54, 5179-5189. [CrossRef]

29. Venkadesan, G.; Muthusamy, J. Experimental investigation of $\mathrm{Al}_{2} \mathrm{O}_{3} / 8 \mathrm{YSZ}$ and $\mathrm{CeO}_{2} / 8 \mathrm{YSZ}$ plasma sprayed thermal barrier coating on diesel engine. Ceram. Int. 2019, 45, 3166-3176. [CrossRef]

30. He, G.; Fan, H.; Ma, L.; Wang, K.; Liu, C.; Ding, D.; Chen, L. Dumbbell-like ZnO nanoparticles-CeO 2 nanorods composite by one-pot hydrothermal route and their electrochemical charge storage. Appl. Surf. Sci. 2016, 366, 129-138. [CrossRef]

31. Pikalova, E.Y.; Murashkina, A.A.; Maragou, V.I.; Demin, A.K.; Strekalovsky, V.N.; Tsiakaras, P.E. CeO ${ }_{2}$ based materials doped with lanthanides for applications in intermediate temperature electrochemical devices. Int. J. Hydrogen Energy 2011, 36, 6175-6183. [CrossRef]

32. Scibioh, M.A.; Kim, S.K.; Cho, E.A.; Lim, T.H.; Hong, S.A.; Ha, H.Y. Pt-CeO $2 /$ C anode catalyst for direct methanol fuel cells. Appl. Catal. B Environ. 2008, 84, 773-782. [CrossRef]

33. Fornasiero, P.; Balducci, G.; Kašpar, J.; Meriani, S.; di Monte, R.; Graziani, M. Metal-loaded $\mathrm{CeO}_{2}-\mathrm{ZrO}_{2}$ solid solutions as innovative catalysts for automotive catalytic converters. Catal. Today 1996, 29, 47-52. [CrossRef] 
34. Trovarelli, A. Structural and oxygen storage/release properties of $\mathrm{CeO}_{2}$-based solid solutions. Comments Inorg. Chem. 2006, 20, 263-284. [CrossRef]

35. Khan, A.L.; Dhanjai; Jain, R. Fabrication and optimization of polypyrrole/cerium oxide/glassy carbon sensing platform for the electrochemical detection of flupirtine. J. Appl. Electrochem. 2020, 50, 655-672. [CrossRef]

36. Karimi, S.W.; Husain, M.; Hosseini, P.A.; Azar, M.R. Ganjali, Rapid and sensitive detection of hydrogen peroxide in milk by Enzyme-free electrochemiluminescence sensor based on a polypyrrole-cerium oxide nanocomposite. Sens. Actuators B Chem. 2018, 271, 90-96. [CrossRef]

37. Mohanapriya, M.K.; Deshmukh, K.; Ahamed, M.B.; Chidambaram, K.; Pasha, S.K.K. Influence of cerium oxide $\left(\mathrm{CeO}_{2}\right)$ nanoparticles on the structural, morphological, mechanical and dielectric properties of PVA/PPy blend nanocomposites. Mater. Today Proc. 2016, 3, 1864-1873. [CrossRef]

38. Seema, S.; Prasad, M.V.N.A. Studies on DC conductivity and LPG sensing behaviour of nanostructured polypyrrole-CeO 2 composites. AIP Conf. Proc. 2018, 1989, 030019. [CrossRef]

39. Benmouhoub, C.; Agrisuelas, J.; Benbrahim, N.; Pillier, F.; Gabrielli, C.; Kadri, A.; Pailleret, A.; Perrot, H.; Sel, O. Influence of the incorporation of $\mathrm{CeO}_{2}$ nanoparticles on the ion exchange behavior of dodecylsulfate doped polypyrrole films: Acelectrogravimetry investigations. Electrochim. Acta 2014, 145, 270-280. [CrossRef]

40. Husain, M.U.; Shariq, F.; Mohammad, D.C. Electrical conductivity and liquefied petroleum gas sensing application of polythiophene/zinc oxide nanocomposite. Materialia 2020, 9, 100599. [CrossRef]

41. Husain, S.; Ahmad, S.; Mohammad, F. Electrical conductivity and alcohol sensing studies on polythiophene/tin oxide nanocomposites. J. Sci. Adv. Mater. Devices 2020, 5, 84-94. [CrossRef]

42. Husain, S.; Ahmad, F.; Mohammad, F. Polythiophene/graphene/zinc tungstate nanocomposite: Synthesis, characterization, DC electrical conductivity and cigarette smoke sensing application. Polym. Polym. Compos. 2020, 1-12, in press. [CrossRef]

43. Husain, S.; Ahmad, S.; Mohammad, F. Thermally stable and highly sensitive ethene gas sensor based on polythiophene/zirconium oxide nanocomposites. Mater. Today Commun. 2019, 20, 100574. [CrossRef]

44. Husain, S.; Ahmad, S.; Mohammad, F. Synthesis, characterisation and ethanol sensing application of polythiophene/graphene nanocomposite. Mater. Chem. Phys. 2020, 239, 122324. [CrossRef]

45. Calvache-Muñoz, J.; Prado, F.A.; Rodríguez-Páez, J.E. Cerium oxide nanoparticles: Synthesis, characterization and tentative mechanism of particle formation. Colloids Surf. A Physicochem. Eng. Asp. 2017, 529, 146-159. [CrossRef]

46. Jayakumar, G.; Irudayaraj, A.A.; Raj, A.D. A comprehensive investigation on the properties of nanostructured cerium oxide. Opt. Quantum Electron. 2019, 51, 312. [CrossRef]

47. Jayakumar, G.; Irudayaraj, A.A.; Raj, A.D. Investigation on the synthesis and photocatalytic activity of activated carbon-cerium oxide (AC-CeO ${ }_{2}$ ) nanocomposite. Appl. Phys. A Mater. Sci. Process. 2019, 125, 742. [CrossRef]

48. Ansari, M.O.; Mohammad, F. Thermal stability and electrical properties of dodecyl-benzene-sulfonic-acid doped nanocomposites of polyaniline and multi-walled carbon nanotubes. Compos. Part B 2012, 43, 3541-3548. [CrossRef]

49. Ansari, M.O.; Mohammad, F. Chemical thermal stability, electrical conductivity and ammonia sensing studies on p-toluenesulfonic acid doped polyaniline: Titanium dioxide (p TSA/Pani: $\mathrm{TiO}_{2}$ ) nanocomposites. Sens. Actuators B Chem. 2011, 157, 122-129. [CrossRef]

50. Wang, S.; Kang, Y.; Wang, L.; Zhang, H.; Wang, Y.; Wang, Y. Organic/inorganic hybrid sensors: A review. Sens. Actuators B Chem. 2013, 182, 467-481. [CrossRef]

51. Bai, H.; Shi, G. Gas sensors based on conducting polymers. Sensors 2007, 7, 267-307. [CrossRef] 